\title{
JERÓNIMO MENDIETA: \\ RAZÓN BARROCA, DELIRIO INSTITUCIONAL
}

POR

\author{
Mario Cesareo \\ Vassar College
}

Para Europa, el Descubrimiento y Colonización de América constituyó un dato que la imaginación religiosa metropolitana intentó reducir a los modelos discursivos propios de su experiencia acumulada en territorio europeo, asiático y africano. El modelo privilegiado fue el de las cruzadas. El movimiento cruzado se había articulado, a nivel simbólico, desde un intento por liberar la ciudad sagrada del "moro impío". Se trataba, en términos discursivos, de la restauración simbólica de una materialidad pervertida, de una corporalidad profanada. La liberación consistiría en la reimplantación del orden sacro. A estas características generales es necesario sumar, en el caso español, los efectos de la expansión nacional de la Reconquista, donde el ideal unitario se conjugaba desde la pureza de sangre y la unidad religiosa, política y territorial ibérica. La empresa militar expansionista de la Cruzada era vista como un extender del cuerpo cristiano y un peregrinar hacia el símbolo terreno de la Ciudad de Dios. Desde esta perspectiva simbólica, la Cruzada se configura en el modelo discursivo religioso de la expansión imperialista europea. Ya en ella encontramos los motivos de la constitución de un cuerpo popular heroico, único y en expansión, ocupado en un peregrinar pletórico de ira para liberar la ciudad sagrada; tarea que se lleva a cabo por medio del exterminio del orden simbólico (satánico) predominante en ella. El fuego de esa guerra es de carácter purificador, en él el cruzado gana acceso a un nuevo cuerpo regenerado y limpio de pecado. La liberación del Santo Sepulcro es, en términos simbólicos, el renacer de un cuerpo que gana su ingreso a la utopía desde la violencia heroica. El espectáculo épico de la violencia histórica coincide, entonces, con la develación de una materialidad sagrada; los trabajos que el héroe asume transforman esa materialidad en estandarte y espectáculo desde el que se revela Dios sobre la tierra.

La peregrinación en su modalidad mediterránea —el discurso de la cruzada - genera una sensibilidad de orden épico, en la que el héroe despliega su sabiduría y violencia en el sometimiento de fuerzas antagónicas en un mundo que no es morada sino circuito poblado de pruebas y peligros. El héroe no está allí para descubrirlo sino para domeñarlo; su destino final es lo sagrado. Su viaje mundano es sólo una necesidad histórica imprescindible a la restitución del orden simbólico y la claridad sígnica del circuito alegórico.

A diferencia de Europa, en América la expansión mercantilista fue experiencia histórica. El Descubrimiento auguró la realización de la Buena Nueva cristiana. Hecho que puso en movimiento una estética de realización utópica, que generó una actitud ex- 
perimental y atrevida por parte de los primeros misioneros, diseñadores de diversos órdenes institucionales con que intentaban materializar la utopía cristiana (Hanke). Rápidamente, sin embargo, la Conquista cedió a la burocratización colonial. La Iglesia intentó hacerse orgánica a la objetividad americana (Zubillaga), al tiempo que esa objetividad era sujeta al rediseño mercantilista. El movimiento expansivo del momento colonizador fue reemplazado por un intento de incorporación, etapa de ardua organización política y construcción institucional; momento beatífico, de moroso habitar en la materialidad americana. Con el asentamiento del orden mercantilista, el territorio americano comienza a desnudar sus graves dislocaciones étnicas, culturales, económicas e ideológicas. Las nuevas relaciones sociales, captadas desde el cara a cara de la experiencia misionera, hicieron posibles y necesarias formas inéditas de plasmación estética que resultarían en la crisis de la alegoría cruzada. El carácter humano de las poblaciones indígenas sometidas al acelerado consumo de sus fuerzas vivas revelaría el carácter sacrificial de las relaciones de producción europeas de cara al nuevo mundo, acentuando la dimensión existencial de un indígena que, de victimario, monstruo, antropófago, se convertía en víctima. El espectáculo de la muerte innecesaria humanizaba al indígena, des-abstrayéndolo, restituyendo la carne a su persona, sacándolo del marco alegórico de las representacion cruzada para inscribirlo en el circuito cristiano de la materialidad sufriente. En esta situación, la Iglesia intentaría plasmar su proyecto ideológico cristiano desde la materialidad americana (Dussel) y a través de el orden mercantilista. Como consecuencia de este doble gesto, el discurso y las prácticas religiosas en esta nueva etapa llegan a su máximo desgarramiento. El pensamiento, incapaz de resolver las aporías de la empresa cristianizante sobrepasa los límites de la alegorización europea, lanzándose al delirio y la derelicción.

El nuevo discurso religioso, de esta manera, está determinado por la dinámica de la institucionalización eclesiástica en territorio americano. La disolución de la alegoría metropolitana en la experiencia de la materialidad colonial convierte al cruzado en antropólogo y hermeneuta. Las distintas estrategias que resultan de este nuevo posicionamiento americano nos permiten escudrinar los amplios territorios de la imaginación utópica así como los estrechos límites de su consecución histórica.

En lo que sigue, intentaremos captar las diversas modulaciones imaginativas mediante las cuales la materialidad americana fue entendida y representada por del discurso y la práctica religiosa de Jerónimo de Mendieta (1525-1604) -religioso franciscano, evangelizador, misionero, y secretario del Padre Provincial de la provincia del Santo Evangelio quien residió por más de sesenta años en Nueva España y fue el redactor oficial de su Orden. El resultado de esta investigación sugiere la coexistencia de sensibilidades altamente conflictivas. Será en la derelicción a través del espacio abierto por un orden incoherente y pletórico de sensibilidades — abarrotadas en la textualidad colonial— que se planteen y resuelvan imaginariamente las diversas tensiones ideológicas, institucionales y existenciales de la experiencia de Indias. En ese delirio imaginativo, el cuerpo adquirirá dimensiones simbólicas y prácticas que le posibiliten un habitar pleno de sentido en la circunstancia colonial y le ayuden a resolver las aporías que tensionan su discurso. Analizaremos este fenómeno mediante un análisis de la Historia eclesiástica indiana (HEI, de aquí en adelante) y su nutrida producción epistolar — recopilada por García Icazbalceta en su Códice Mendieta $(C M)$ 
La $H E I$ narra la historia de la Conquista y Colonización de América desde la llegada de Hernán Cortés a México (1528) hasta el fin de siglo. Se presentan cronológicamente los principales hechos políticos, militares e institucionales de la Colonia, incluyéndose la reproducción de cartas, ordenanzas, testimonios, bulas papales y otros documentos relacionados a los territorios ultramarinos. El trabajo concluye con un catastro de las vidas y hazañas de los santos y mártires que hicieron posible la evangelización americana. Historiográficamente, la HEI identifica dos épocas en la colonización: una Edad Dorada, coincidente con el proceso de la Conquista de Hernán Cortés y la llegada de los primeros misioneros a la Nueva España, y un presente degradado, cuyos inicios coincidirían con la muerte del gobernador Luis Velasco.

El diseño de la $H E I$ es el resultado de una meditación sobre la historia pasada y presente que intenta restituir organicidad y continuidad de sentido a la experiencia colonial. Acorde con esto, se trata de un texto donde se entrecruzan modalidades discursivas altamente contradictorias, que son erigidas y desmanteladas a medida que se avanza en el discurso de la historia colonial. El resultado de esta estrategia es doble: por un lado, la producción de lo que llamaremos el parapeto corporal; por el otro, la producción de un parapeto documental y hagiográfico que se encuentra en los límites del discurso histórico épico/providencialista, y los umbrales del tratado, la monumentalización hagiográfica y la denuncia testimonial.

La descripción de la tarea colonizadora de América sigue los lineamientos del discurso cruzado: el Descubrimiento es visto como "maravilla" providencial donde Colón, Cortés, la Santa Inquisición y los reyes católicos son instrumentos escogidos por Dios para su labor salvadora de manifestación testimonial y conversión indígena (HEI 1: 12). Al plantearse la expansión mercantil como continuación de la Reconquista -recurso ya iniciado por Colón (Zamora) - la tarea apostólica queda enmarcada en un proceso civilizatorio, exorcizante y homogenizador que continúa en América la "limpieza" de la "espurcicia" mahometana comenzada en la península; tarea otorgada a España como premio al "santísimo celo y heroica hazaña" mostrada en sus guerras de reconquista (HEI 1: 1315).

El mito cruzado de la Reconquista supone la identidad y continuidad del cuerpo político y económico mercantilista. Los representantes del poder espiritual (Roma), los administradores del poder secular (Reyes Católicos) y los aventureros, comerciantes y militares ultramarinos (adelantados, conquistadores, virreyes, gobernadores) constituyen un cuerpo a la vez nacional y universal. El pilar de esta Edad Dorada es Hernán Cortés, prototipo del héroe y síntesis del militar y el predestinado misionero que abre las puertas de la evangelización; su nacimiento responde al designio divino, convirtiéndolo en instrumento llamado a exorcizar y civilizar un territorio sumido en la barbarie (HEI 1: 108). En Cortés, el ejercicio de la violencia surge como una necesidad exorcizante y se justifica mediante la alegorización histórica y la satanización del otro (HEI 1: 108).

Ese orden satánico imperante en la ciudad idólatra causa un descalabro cósmico, un escándalo, que debe ser rectificado. Mendieta encuentra en la mitología popular azteca señales que dan sentido a esta circunstancia traumática y dislocadora. La ebullición de los mares, la aparición de pirámides de fuego, los agüeros, prodigios, anomalías y otros extraordinarios acontecimientos naturales anuncian la llegada de Cortés. Al sumirse el 
cataclismo cultural de la Conquista en una rebelión del orden natural, la dislocación, la pérdida del sentido común y verosimilitud cotidiana coloniales quedan asimiladas a una conspiración de la ley natural y divina. Por medio de este recurso se asigna carácter trascendente a lo que, de otra manera, sería el resultado de un desarrollo económico dirigido por intereses de orden privado. El cataclismo alegórico del orden natural permite universalizar y naturalizar esos intereses convirtiéndolos en espectáculo heroico.

Mendieta salva el marco idílico y justificatorio de la violencia conquistadora al presentar el proceso colonial como si hubiese sido regido por la razón ética cristiana. Fenómeno que se logra mediante un discurso histórico alegorizante, que se pasea morosa, amorosa y novelescamente por la ruina histórica.

Y no se tenga por superfluo y vano el poder por tan menudo y extenso los días que estos siervos de Dios en el discurso de este viaje pasaron, los puertos que tomaron. [...] Porque si para escribir historias profanas y henchir sus libros los autores se aprovechan de mil menudencias y cosas impertinentes, pintándolas con muchos colores retóricos, mostrándose cronistas puntuales: diciendo de uno que después de los muchos triunfos y victorias alcanzadas se iba a espaciar a la ribera del mar, y a trebejar con las conchas de los caracoles, ostras y almejas de él: y de otro que viniendo vencido de la batalla pidió a un villano un jarro de agua (cosas de poco momento), con más razón yo escribir estas menudencias (si así se sufre llamarlas), pues escribo historia verdadera y no forjada de mi cabeza, no profana sino eclesiástica, ni de capitanes del mundo sino celestiales y divinos que subjetaron con grandísima violencia al mundo, demonio y carne, y a los príncipes de las tinieblas y potestades infernales (HEI 1: 127).

Esta modalidad narrativa está vinculada al individualismo humanista protoburgués y al modelo heroico cortesiano de las Cartas de Relación (Vidal Pastor). Sin embargo, en Mendieta la visión aristocratizante de Cortés se convierte en artificio que permite penetrar la sicología de los personajes heroicos con el propósito de espectacularizar su grandeza espiritual. La morosidad del relato histórico en Mendieta es la forma de garantizar una intencionalidad que, de otra manera, quedaría desmentida por los acontecimientos históricos y las ganancias temporales en que esos héroes quedan implicados mediante el usufructo del sistema económico y político colonial.

La reproducción de documentos oficiales - bulas papales, cartas de los reyes católicos y otros funcionarios - el mito de la Reconquista y el héroe cortesiano permiten proponer la época apostólica como un período de unidad religiosa y militar, donde la institución castrence se perfila como institución que garantiza las condiciones de posibilidad de la empresa evangélica - porque ésa es su razón de ser y porque así lo desea Roma, la Corona, y sus representantes de Indias, fieles intérpretes de la voluntad divina.

Muerto Cortés, y acabada la primera etapa de la Conquista, los franciscanos aparecen como responsables de la supervivencia colonial, prosiguiendo la dirección de los asuntos comunitarios ante el vacío de poder generado por la pérdida del capitán modélico (HEI 1: 140). Los frailes se presentan como argamasa que hace posible al edificio social. Por un lado, asegurando la continuidad del poder, subsanando las divisiones intestinas de los españoles y desarrollando las funciones de seguridad y espionaje necesarias para la preservación del orden metropolitano (HEI 1: 140). Por el otro, preservando al indígena 
de su total exterminio - labor revelada no como salvación del aborigen para sí mismo, sino como mantenimiento de la fuerza de trabajo (HEI 1: 140-1).

El español, llevado por intereses individuales y anticomunitarios, persigue al misionero. La limitación ideológica de la razón mercantilista le impide ver más allá de sus estrechos intereses de clase en tanto que conquistador:

Y lo bueno es que en lugar de buenas gracias, siempre por ello los frailes las han llevado malas, quejándose los españoles y murmurando de ellos, que les hicieron quitar los esclavos y que no les dejan aprovecharse de los indios como querían. Y lo que querían es servirse de ellos de tal manera que se acabasen de presto, porque no tienen cuenta con más de que haya para su tiempo (HEI 1: 140).

Ante esta situación, el religioso suple la visión totalizadora y comunitaria del héroe épico y mantiene a raya las inclinaciones depredadoras y bárbaras de las huestes españolas, dotándolas de una concepción civilizatoria.

La función aglutinante y conservadora del proyecto de la colonización-comoReconquista entra en contradicción con los presupuestos de la Conquista como establecimiento de un orden colonial de extracción de riquezas, basado en el sometimiento de la fuerza trabajadora a diversas formas de esclavitud y servidumbre. En otras palabras, aquellas relaciones de producción semi-feudales propias de la experiencia española, que constituyeron las bases materiales del proyecto de evangelización como Reconquista, registran serias transformaciones al desnudarse su carácter sui generis como resultado de la consecución del poder institucional y la entrada al período de la burocratización colonial. Las transformaciones inherentes al paso de una economía nacional-metropolitana a un sistema colonial-periférico son la materialidad que pone en crisis la argumentación épica del discurso de la Conquista, elaborado para dar cuenta de una situación ya superada históricamente.

Perdido el homogéneo liderazgo burocrático-militar de la etapa anterior y suplantados los protocolos verticalistas de aquél por las anónimas y conflictivas fuerzas ciegas de la competencia económica y política en que se sume el cuerpo social español en el nuevo continente, la ciudad ideal adquiere visos de orfandad. La proliferación de autoridades, cuyas esferas de influencia se sobreponen unas a otras, sumada a la lejanía de la autoridad central, escenifican un vacío de poder donde los intereses personales se enseñorean de la dinámica social provocando el caos, el enmascaramiento y la confusión generalizada.

En el paradigma de la orfandad americana la historia de las guerras internas coloniales aparece como una alegoría histórica sobre la paternidad y conducción moral de América. Esa disputa por el derecho a la regencia de la colonia se monta desde una economía simbólica y de poder derivada del modelo de la familia patriarcal y mediatizada por la lógica mercantilista de la explotación de los recursos naturales de Indias -donde el indígena y el negro son vistos como materia prima a ser transformada e inserta en el circuito económico metropolitano.

El lugar dejado por la ausencia del conquistador es disputado por el español, el religioso y el sacerdote indígena, figuras que ocupan los espacios simbólicos de la babilonia colonial, la reducción y la barbarie idólatra, respectivamente. En lo histórico, este conflicto 
se dirimió de forma práctica: la lucha territorial y jurisdiccional acabó en la formación de repartimientos y encomiendas que pusieron a disposición económica, política y jurídica del español la materialidad del indígena americano; las reducciones y los "pueblos" resultaron en fallidos intentos de evangelización pacífica, y la creación de sistemas de producción y consumo altamente desarrollados que atendiera a las necesidades comunitarias bajo la dirección política de una oligarquía indígena bajo directiva eclesiástica; el cerco de la barbarie fue destruído por la guerra a ultranza contra los indígenas "no cristianos" que constituían una presencia fantasmagórica en los confines de la ciudad cristiana, en los territorios de la "barbarie" aún no incorporada al orden metropolitano.

El circuito simbólico de la orfandad abre las puertas a una economía metafórica donde los sectores en pugna por la paternidad putativa adquieren características corporales que abarcan la barbarie idólatra, el vampirismo español y la tutelaridad misionera, enjambre de cuerpos que pululan el mundo colonial y van configurando el espectáculo de la nueva alegoría cristiana.

El indígena no cristianizado es visto como radicalmente distinto del de la reducción. Se enfatiza su bestialidad, ceguera y desconocimiento de las normas más elementales de la vida social, la que se reduce a la conducción de guerras permanentes y sacrificios humanos. La bestia idólatra es de una confección humana inferior a la del indio cristianizado, es indócil, poco inteligente y carece de la mansedumbre del segundo. En el motivo de la presencia bárbara del indígena no cristianizado, en la dinámica de la frontera imperial, radican las condiciones que hacen posible y necesario el discurso cruzado que, como un enclave en la correspondencia de Mendieta, sigue cumpliendo un rol fundamental en explicar y legitimar la persistencia de condiciones materiales marcadas por la expansión de la Conquista.

América escenifica el conflicto entre la civilización y la barbarie, y este proceso supone la necesidad de la expansión territorial española y la población del territorio así ganado por el cuerpo español organizado bajo una lógica militar; producción de una ciudad amurallada que repite los manerismos de la antigua gesta de la Reconquista, empresa multiplicadora de la mismidad en lucha descarnada por el desalojo del otro de un espacio limitado. Cultura que sitia y es sitiada por la otredad, de cariz militar, no negociador, obsesionada por su propia pureza — percibida como única garantía de supervivencia.

La extirpación de idolatrías, la destrucción del orden simbólico indígena, la expulsión de brujos y la profanación de sus objetos sagrados son algunas de las tareas que conforman la política de tierra arrasada mediante la cual el religioso hace tabula rasa de una materialidad americana que se concibe como irredimible, que debe quedar obliterada por la ira de Dios.

La discontinuidad en el desarrollo social y político, el carácter móvil de la colonización y su desigual afianzamiento histórico en diversas zonas del territorio americano, permitieron mantener vivas las premisas, dinámica y necesidad del emplazamiento cruzado como una posibilidad imaginativa más dentro del universo discursivo y las prácticas cristianas.

Textualmente, sin embargo, la barbarie idólatra es una presencia apenas sugerida, fantasmagórica, en tanto Mendieta sólo mira de soslayo fuera de la ciudad amurallada; su lugar predilecto no es la población de guarnición de la frontera sino la ciudad virreinal, con sus minas y plantaciones, su boato, sus iglesias y edificios municipales, sus mercaderes y su rey: el medro. 
Cuando Mendieta se ubica en el terreno ya ganado al bárbaro, una vez destruído el orden satánico de la barbarie indígena y erecta la materialidad de la ciudad cristiana, el orden épico del discurso cruzado es cuestionado. De hecho, Mendieta hace un llamado de atención sobre la necesidad de utilizar nuevos patrones simbólicos en el entendimiento del aborigen americano de la estabilización, apartándose de los modelos basados en el paradigma de la Reconquista (CM 2: 11-12).

El nuevo modelo se construye desde un mito opuesto y complementario al de la barbarie idólatra, mediante el cual se intenta captar la fenomenología cotidiana de las relaciones entre el español y el indígena desde la lógica misionera. Este paradigma surgirá de la producción discursiva de una corporalidad inmaculada, moldeable, redimible, cristianizable, plasmada en la figura del indio-párvulo.

Las bases materiales de la creación del párvulo quedan resumidas en ciertos hechos que constituyeron hitos fundamentales en la experienciación europea del indígena. Por un lado, su conciencia del superior desarrollo científico y tecnológico en la comprensión y dominio de la naturaleza por parte del español, expresada en su dominio del arte de la guerra, la producción de armamentos y su capacidad organizativa. Por otro, su mayor destreza en el entendimiento y manipulación del imaginario social, resultante en el dominio ideológico y temporal de grandes masas de aborígenes para la satisfacción de las necesidades de una minoría europea. Habría que agregar, aún, la capacidad del español de traspasar el pensamiento mítico indígena con un entendimiento más realista de las relaciones de poder al seno de los diversos modos de producción social - lo que formó el basamento científico del entendimiento maquiavélico característico del estado moderno. Por último, la existencia de un orden legal y práctico donde el aborigen es, de hecho y de derecho, un menor de edad a disposición de la voluntad metropolitana.

El espectáculo de la minusvalía indígena fue interpretado de múltiples maneras: como signo de inferioridad racial, incapacidad moral, bestialidad; como resultado de variantes geográficas, problema teológico, resultado histórico. Las discusiones sobre la humanidad del indígena y la puntualización de sus potencialidades y carencias ocuparon infinidad de documentos y dieron lugar a una legislación tutelar generada en España y destinada a mediar ese frágil posicionamiento del indio ante las autoridades coloniales (Hanke). Lo que no se discute es la realidad de esa minusvalía. Ya a su favor o en su contra, el indio es representado como ser destinado al usufructo. Supervisado en su culto religioso, físicamente debilitado por un régimen de explotación desconocido en la cultura precolombina, afectado por enfermedades banales para el español, y amedrentado por un orden represivo, aparece como pusilánime, tímido y obediente. En otras palabras, las relaciones de producción coloniales crean la realidad institucional de un indio minusválido; realidad históricoeconómica que se naturaliza mediante el mito del indio-párvulo que Las Casas, Mendieta y otros destinan a la creación de una legislación tutelar para su protección -estrategia que, en su polo negativo, perpetuó una visión reificada del indio y entorpeció toda apertura antropológica a la experiencia del vencido.

El mito del indio-párvulo no conlleva la utopía de un crecer hacia la mismidad del colonizador; supone, por el contrario, un perpetuo estado de infantilidad (HEI 2: 60) que se mantendrá "de AQUí a que Dios benga a juzgar el mundo [...] porque es ya aquel su ser, talento y capacidad natural que Dios les quiso comunicar" (CM 1: 255-56). El párvulo, en 
su estado de adultez cronológica, no llega a sobrepasar la condición física e intelectual de un niño; según asegura Mendieta, "el talento y capacidad de los indios comúnmente es como de mozuelos de hasta diez ó doce años" (CM 2: 8). El párvulo es potencialidad, inacabamiento a ser suplementado, materialidad bruta para la transformación, "tabla rasa" y "cera blanda" - los indios son "aptos para imprimir en ellos cualquiera buena doctrina" (CM 2: 11). Ingenuos y carentes de malicia, "de tanta pureza de alma, que no saben pecar [...] ni saben murmurar, ni quejarse de nadie, ni reñir aun a los muchachos traviesos" (HEI 2: 61-62). A diferencia del español experto en la manipulación de las máscaras sociales, el indio es simple rostro en el que todo puede ser indagado. El desconocimiento de la lógica picaresca que permea la sociedad colonial hace del párvulo una presa fácil para la superexplotación. Este hecho, unido a las condiciones de rapiña imperantes al seno del cuerpo social, inaugura la reversión de los términos civilización y barbarie del discurso cruzado - lo que lleva a Mendieta a decir: “plega á Su Majestad Divina, que nosotros, con nuestra presunción de cristianos viejos y de muy entendidos y capaces, no nos hallemos burlados por haber hecho burla de los mal vestidos" (CM 2: 36).

Ese mundo al revés revela la crisis del sistema alégorico que caracterizaba a la historia apostólica de los primeros años y abre las puertas a una nueva búsqueda que ha de suplantar la verosimilitud cruzada, basada en la concordancia del referente (cristiano) y el signo (español), en un nuevo sistema de representación asentado en la noción del escándalo. Una concordancia tal la suponía, como viéramos anteriormente, el mito de lo nacional español —en su dimensión de Reconquista - frente a la presencia satánica del otro. Este mito de la nacionalidad, en el cual se sintetizaba y legitimaba el ordenamiento monárquicoseñorial y mercantilista, hace crisis, obligando al deslinde de los términos "español" y "cristiano":

[...] es necesarísimo provea S. S. de remedio en un infernal abuso que los españoles han plantado en toda la región destas Indias Occidentales, y es de llamarse ellos cristianos, á diferencia de los naturales de la tierra, puesto que todos son baptizados; y así es plática general de los españoles, hablando con los indios, para decir "llámame á aquel español", o "dile tal cosa á aquel español", o "ve á casa de fulano español", decir "llámame á aquel cristiano", 6 "dile esto á aquel cristiano"; cosa absurdísima, y que espanta no haber tenido cuidado los Prelados de estas partes de que se ponga remedio en ella, porque es persuasiva á los indios para que nunca se tengan por verdaderos cristianos; y es cosa clara que diciéndole el español al indio "llámame á aquel cristiano", por el español, luego en su pecho formará una consecuencia y dirá entre sí: "luego yo, por ser indio, no soy cristiano"; y otros habrá que viendo tan malas obras como las que comunmente hacen los que se intitulan cristianos, tomarán odio á este nombre, y dirán "mucho en buenhora séte tú cristiano, que yo no lo quiero ser". Por evitar tantos y tan graves daños como deste mal abuso se pueden seguir, conviene quitarlo con todo el rigor del mundo, aunque sea con pena de excomunión á los que scienter no lo quisieren dejar, y que se proceda contra ellos como contra perturbadores de la cristiandad y de la conversión de las gentes (CM 1: 258-9).

La problematización de la relación entre monarquía y cristianismo se expresa en la incapacidad del marco representativo de captar la realidad sobre la que versa, iniciándo un escándalo discursivo. En este nuevo marco alegórico, la realidad propone formas alternativas 
de comprensión de la Buena Nueva, cuya inescrutabilidad es mediada por la presencia de lo degradado. Es justamente en el terreno de lo ínfimo, lo bajo, la materialidad despreciada por la cultura hegemónica, donde se hallan las claves de un misterio divino que supone la ruptura de la verosimilitud colonial, la burla de los protocolos hegemónicos implícita en el "no nos hallemos burlados por haber hecho burla de los mal vestidos."

La historia secular está alli para "confundir", para provocar un esfuerzo hermenéutico capaz de dar vuelta la apariencia y encontrar, en el escándalo, el significado divino de lo acaecido.

Considero [...] que no sin misterio llamó Dios á estos indios á su fe católica y al gremio de la Iglesia á cabo de tantos años que sus padres y antepasados estuvieron en poder del demonio, y en tales tiempos como en los que estamos, y siendo tan bajos como (á nuestro parecer) son de entendimiento, sino para verificar en este su llamamiento y elección, la que siempre ha usado para con sus criaturas, que es (como dice Sanct Pablo) elegir á los que parecen tontos al mundo para confundir á los sabios del mundo, y á los flacos para confundir á los fuertes, y á los bajos y despreciados y que parecen no tienen ser, para confundir y destruir á los que á su parecer tienen ser y valor (CM2: 30$)$.

En la estética del escándalo la mirada cristiana comienza a enfocarse en la problemática y cotidianidad del indígena y el esclavo, en las relaciones de dominio imperantes. Ante este espectáculo, la ciudad colonial se torna en grotesca parodia del mandato divino, donde se deconstruyen e invierten el mártir y el cruzado, figuras claves del discurso cristiano, siempre implicadas en el enfrentamiento entre la civilización y la barbarie.

Mediante la reconstrucción del marco sociohistórico del martirio, Mendieta hace que este último aparezca como resultado de lo político (HEI 1: 27-32). En lugar de la predeterminación teológica característica del discurso hegemónico, el circuito beatífico ubica la acción sacrificial dentro de parámetros políticos, sistémicos y económicos que desmitifican el acontecer histórico colonial. De allí que los éxtasis y paroxismos del mártir, tan típicos en la descripción hagiográfica - cuyo máximo exponente fue João de Lucenasean desplazados por una concepción altamente trágica de la muerte, que es representada como el espectáculo de un acabarse agónico, enmarcado en el dramático resultado del error histórico. Dentro de este circuito unificado y unificador de la muerte, la reliquia no es ya sólo el cuerpo epifánico del mártir, sino los despojos, el sobrante de los espolios de la colonización.

[...] y así nos parece que añadir ahora los tributos (como se añaden) á gente que de cada día van más en diminución, y que palpablemente vemos que se van consumiendo, es inhumanidad y crueldad; y que entender en sólo esto y con toda la eficacia del mundo, sin admitir razón en contrario, y sin compadecerse en verlos morir como moscas un Visitador [...] parece que es poner mácula y sospecha en la Real Persona, de poco amor á sus vasallos, $\delta$ de demasiada codicia, porque para los que sentencian por el exterior y echan juicio á montón, no se da con esto otra ocasión sino de decir que S. M. se quiere aprovechar el poco tiempo que durare, de los indios, aunque para adelanto no quede reliquia de ellos (CM 1: 26-27).

El indio-como-reliquia no sólo se incorpora al circuito del cuerpo crístico sino que es, 
además, una presencia cuya revelación es ambivalente: apunta a ese sacrificio y, por lo tanto, a la salvación; pero también, y fundamentalmente, señala la tragedia del etnocidio y la implantación de la muerte como silencio, como pérdida de la memoria histórica, como muerte absoluta, genérica y existencial.

y en esto es cosa cierta que por intervenir la desenfrenada cobdicia que tanto reina [...] les destruyen estos reinos sustentando y obrando una crueldad tan inaudita como es destruir y asolar tan amplísimas regiones, no dejando memoria de los innumerables moradores que en ellas hallaron (CM 1: 245).

Ante ese silencio, se impreca al monarca su obligación de preservar a los indios aún vivos como una manera de monumentalizar o memorializar el espectáculo de una etnia en extinción (CM 1:36).

La problematización beatífica del martirio, entonces, expresa una teología que entiende la corporalidad humana desde una perspectiva radicalmente diferente a la del discurso cruzado. Si en aquél se partía desde una concepción dualista de la persona -dualidad de cuerpo y alma - en éste predomina la noción tomista de la unidad sustancial — ser humano como "espíritu encarnado" (Ruiz de la Peña). El cuerpo es un momento sustancial, trascendente e inevitable de la persona humana; es el asiento del misterio más trascendente del perfil religioso cristiano: la encarnación histórica de Dios (Williams 128-47). De esta manera, la propuesta tomista resulta en una concepción de la persona humana donde la muerte aparece como un hecho existencial y no como un mero paso del alma al reino del más allá (Ruiz de la Peña 13). La muerte adquiere visos de acontecimiento trágico: muerte como lo que, sin paliativos, "arrebata la vida" (Ruiz de la Peña 18). La dimensión trágica de la muerte como espectáculo de la "vida arrebatada" se trasunta en la conciencia del estado de finitud, expresado en una estética de la muerte como instancia agónico-existencial. Esta visualización del cuerpo permite incorporar al sufrimiento como un elemento fundamental en la estética de la representación colonial. Desde el espectáculo de ese cuerpo sufriente Mendieta construye su visión profético-apocalíptica del imperio; desde el dolor de ese cuerpo mutilado se arma la poética melodramática de la bestia española ante el desamparo del párvulo americano, en un holocausto ante el cual el historiador interpone su memoria como un desesperado intento de preservación ante la extinción apocalíptica de la muerte y la destrucción indiana.

Para Mendieta, el ordenamiento mercantil constituye un lente distorsionador del espectáculo social americano. El afán de lucro lleva al español a ver la materialidad social desde los colores de las más codiciadas mercancías, lo que le impide percibir la particularidad colonial en sus verdaderos "colores", empantanando al gobernante en el fango de la codicia mercantil, con peligro de perdición eterna para su alma. La distancia entre América y España es mediada por esa relación mercantil que impide una captación no distorsionada.

Y si con temor de errar y por ello desagradar a Dios se deben recebir los cargos de gobierno [...] Àcon qué temor debería aceptar el gobierno de Indias, desde la corte de España, el que nunca las vio, ni sabe de qué color son, salvo el color de la plata y de otras preseas que de Indias llevan? (HEI 2: 87). 
En el fin de lucro radica el motor estético que promueve una imagen falseada del indio, en tanto el carácter instrumentalizador del otro deja a la percepción europea alienada de las condiciones de producción que han hecho posible la "mercadería" creada por el sistema de explotación mercantil. Esta enajenación, unida a los intereses económicos que se benefician del estado de cosas imperante, termina por constituir una estética distorsionante que valida la Conquista desde su discurso épico.

[...] se ha juntado el regosto del oro y de plata que de acá se lleva, y que los hombres mundanos, sin sentimiento de Dios y sin caridad del prójimo, han informado siempre que aquestos indios son una gente bestial, sin juicio ni entendimiento, llenos de vicios y abominaciones, dando a entender que no son capaces de doctrina cristiana ni de cosa buena; creyendo estas cosas y otras semejantes, a que el demonio, nuestro enemigo y la codicia de los haberes del mundo fácilmente persuade a algunos de los que han estado en el consejo de Indias, o privado con los reyes, o de los que acá han sido enviados para gobernar (HEI 1: 20).

En este escándalo de la distorsión mercantilista, el espectáculo de la superexplotación indígena desemboca en la perversión del motivo de la eucaristía, que deviene una práctica antropofágica en un espacio donde los indígenas están "ni más ni menos como ovejas que andan cercadas de lobos hambrientos y deseosos de chuparles su sangre" (CM2:31). Este revés práctico del ritual cristiano es reiterado con insistencia por Mendieta, que ve en el español una presencia vampírica que sacrifica al indio en el altar del medro mercantilista, que lo desangra en lo material, puesto que "como la sanguijuela [le] chupamos la sangre y la vida de aquellos á quien nos allegamos" (CM1: 230); orden canibalístico del repartimiento en que el español es bestia cebada, al acecho de la oveja indígena cristiana (CM 1: $44 ; 245$; 248).

El cuerpo colonial aparece como mutilado, desnudo. El espacio americano "lleva camino de despoblarse en breves días [...] y de perderse en mucho más breve tiempo la cristiandad desta tierra" (CM 1: 42). La Colonia es una república corrupta, un cuerpo exánime que necesita la inyección de un espíritu vivificador.

[...] y la causa de donde proceden tales operaciones en el cuerpo místico desta república es el espíritu que ahora lo rige, que parece inspirar ó tender á estas dos cosas, conviene á saber: sacar mucho dinero de los pobres indios, y desacreditar del todo á los Religiosos [...] Y pues en mano de V. A. está volver la hoja y poner de su mano espíritu que á este cuerpo dé vida [...] pedimos a V. A. se sirva de que esto se ponga por obra, y no permita que así á ciegas se destruya un mundo (CM 1: 42).

El motivo bíblico de la repartición de lo panes, tematizado por la tradición hagiográfica como el banquete escatológico de la conquista, se transforma en el robo de las magras riquezas americanas; el mandato de poblar la tierra se convierte en holocausto (CM 1:2930), por lo que Mendieta escribe al rey: "con la debida humildad suplicamos á V. M. que se cumplan con nosotros aquellas palabras de Cristo: Misericordiam volo et non holocaustum" (CM 1: 132).

En el mundo al revés de la Colonia, la presencia satánica, frustrada ante los logros de la tarea evangelizadora de la edad dorada, 
[...] se esfuerza á la contradecir con todo su poder [...] por todas las vías á él posibles; y como ve que de parte de los mismos indios no hay resistencia, antes toda disposición, y que de parte de los ministros que ellos han menester (que son los Religiosos) está la voluntad muy pronta para ayudarlos, ha usado de un nuevo ardid para que sea de más eficacia el estorbo, y ha sido estragando el pecho de todos aquellos que son é podrían ser parte para favorecer esta obra, de manera que unos debajo de un buen color, y otros debajo de otro con que se persuaden, le sean mal devotos, y no solamente no la ayuden, mas antes le pongan mil impedimentos (CM 1: 104-5).

Las tretas de este mundo picaresco hacen del religioso una figura avocada a la restauración de la verdad escondida bajo los "colores" del engaño. Por eso la función del discurso histórico, para Mendieta, es reconstruir un ojo realista que entienda el espectáculo colonial desde una mirada ética cristiana, no adulterada por el lente distorsionador del interés mercantil. La propuesta de ese ojo implica un posicionamiento corporal de extrañamiento con respecto a la maquinaria económica colonial. Supone la necesidad de replantear el posicionamiento desde donde se confronta la labor histórica. En Mendieta, ese emplazamiento sufre una evolución que lo lleva de la tarea historiográfica de legitimación de la conquista - discurso cruzado - a una postura arbitrista, que lo emplaza en la legalidad de Indias, y cuyo resultado es una serie de estrategias políticas destinadas a aligerar la carga del indio, para desembocar, una vez agotados los recursos institucionales de intercesión, en el emplazamiento de la propia corporalidad como única garantía de efectividad terrena. Se trata, en definitiva, de la sustitución del parapeto documental de la tradición lascasiana por un parapeto corporal. En la base de esta sustitución del texto por el cuerpo se encuentra un entendimiento de los imperativos sistémicos del orden americano que llevan a Mendieta a encontrar la solución del problema colonial en el accionar del religioso como la verdadera historia.

La percepción de la Colonia como espacio de orfandad habitado por el párvulo y merodeado por la presencia rapaz del indio-bárbaro y el vampirismo español lleva a concebir al misionero como figura de interposición, destinada a la protección del minusválido. Si el indígena posee un cuerpo a medias - mutilado, de "pequeñez" corporal, "débil", "flaco", "sin voz"- el religioso ha de desarrollar su corporalidad de manera complementaria a las carencias del otro; para esto, su corporalidad adquiere características ortopédicas. La dimensión ortopédica desemboca en la ventriloquia española. El misionero habla por el indígena, por los "que no tienen siquiera un balido para saberse quejar y pedir el pasto de que tienen necesidad" ( $C M 1: 257)$. Por aquéllos que "no saben abrir la boca, ni aun para manifestar siquiera alguna parte de su daño" (CM 1:227). El indio no puede convertirse en interlocutor ante el poder constituído; de allí que el religioso surja como aquella instancia mediadora capaz de interpelar al rey en su nombre e interés: "[...] y que estos indios sean la gente más pobre, más débil y flaca, más ignorante y más descuidada que ninguna otra nación, nadie lo puede ignorar, pues aun no tienen siquiera aviso, ni acuerdo, ni modo para comunicar y representar á su Rey las necesidades de su república indiana, sino que es menester que otros hablen por ellos y se lo acuerden" (CM 2: 7).

Al mismo tiempo, y complementariamente, el monarca visualiza al misionero como extensión de su corporalidad; mediante él extiende el rey su capacidad perceptiva de los aconteceres coloniales —el cuerpo religioso le permite "ver" y "entender" aquello que no 
presencia - al tiempo que hace posible "actuar" en esa realidad. Las siguientes palabras del monarca hacen evidente esta dimensión del religioso como cuerpo ortopédico, como ojo realista y parapeto material destinado a aminorar el impacto que surge del contacto entre el indio y el español:

El talento y capacidad de los indios ya está bien conocido, que no es más que de pequeños muchachos, mayormente estando tan acobardados y subjetos como están; no hay que aguardar que ellos vuelvan por sí, porque no tienen boca para hablar ni balar, aunque los vayan degollando como a corderos. [...] Si los pobres indios por mi descuido padecen, ha de ser a costa de mi alma. Yo estoy tan lejos, que no puedo ver ni entender, sino en solo lo que me dijeren. Buen gobernador tengo en $\mathrm{D}$. Antonio de Mendoza, buen cristiano es (según la fama que tiene), hombre es prudente, benigno y reportado, y escogido entre millares; pero al fin, hombre del siglo es, hacienda busca, y hacienda ha menester. Criados tiene que le sirven, amigos y allegados tiene, y los oidores lo mesmo; cosa ordinaria es hacer los unos por los otros. Y cosa fácil declinar los que les parece etar muy justificados a lo que les lleva el propio interese o el de los suyos, olvidando a los más remotos. ¿Pues qué haré para más seguridad de mi conciencia? ¿Con qué diligencia o por qué medio mejor la descargaré? Paréceme que poniéndola en manos de hombres desinteresados que no les pueda mover otro interese más que el del servicio de Dios y amor y defensa del prójimo, particularmente del pobre y menesteroso, en lo que es razón y justicia, buscándolos de tal vida y ejemplo, que yo me pueda bien de ello fiar y dar crédito a lo que me dijeren (HEI 2: 77).

De esta manera, entonces, el cuerpo ortopédico del santo, voz del indígena y oído y brazo ejecutor del monarca, sirve a los efectos de prolongar, suplir y conectar los diversos miembros del cuerpo social colonial y el metropolitano.

La dimensión maternal y nutritiva del cuerpo ortopédico misionero se plasma en el motivo de la lactancia. Dentro de esta metáfora, el religioso hace las veces de cuerpo nutritivo que otorga el alimento espiritual, "que es la leche de la Santa Madre Iglesia" (CM $1: 257)$, necesario al cuerpo desvalido del indio, que es convertido a la fe y criado "con la leche y manjar del santo Evangelio" (HEI 1: 199). El otorgamiento maternal y nutritivo de la "leche y manjar" de la espiritualidad es, a la vez, una inseminación paternal que dignifica la materialidad indígena al hacerla pasar de la barbarie idólatra al rango de persona cristiana, proceso entendido como un regenerar iniciado por la asperción -como un "nacer de nuevo"- y el sustento "con la leche y mantenimiento de la doctrina" (HEI 1: 201). E1 religioso es, por lo tanto, madre que sustenta y padre que engendra desde la palabra: “¿Por ventura podrá olvidar o dejar la madre al hijo? Y si ella lo dejare, nosotros no os hemos de dejar, pues sois hijos nuestros, que por la palabra y Evangelio de nuestro Señor Jesucristo os hemos engendrado" (HEI 1: 196).

La dimensión paternal se complementa con una presencia tutelar, de un misionero cuyo cuerpo monumental ha de dar protección, enseñanza y disciplina.

Mas entiéndase que esta su pequeñez [del indio] no nos da en ley natural licencia para que por eso los despreciemos [...] porque no tienen defensa ni resistencia para contra nosotros. Antes por el mesmo caso de ser poco su poder, nos obligan a que nos compadezcamos de ellos como de flacos y menores, y a sobrellevarlos, defenderlos y ampararlos, y volver por ellos, como lo hacen aun los animales irracionales por brutos 
que sean. [...] Por lo cual las leyes humanas todas enseñan y establecen este favor, amparo y defensa a los que pueden y tienen fuerzas, para con los que poco pueden (HEI 2: 106).

La noción de tutelaridad reemplaza la violencia épica por el disciplinamiento, versión desmonumentalizada del castigo disciplinario que marca el tránsito de la ira divina al enfado paternal.

[...] porque puesto caso que muchos dellos están habilitados a entender los misterios de la fe que antes no conocían ni alcanzaban, y otros en artes mecánicas, y otros en cosas particulares de policía humana, y otros muy ladinos en malicias que se les han pegado de los españoles, pero común y casi generalmente perseveran en el ser y capacidad de muchachos que tienen necesidad de tutores y curadores que los guien y rijan con autoridad de padres, y por consiguiente son flacos y párvulos (CM 1: 255-56).

Violencia que el mismo indígena justifica como acto de enseñanza, como medio benévolo, necesario y merecido (HEI 1: 203).

La presencia de la fiera española interfiriendo en las relaciones tutelares entre el indígena y el religioso hace necesaria la reintroducción del modelo cruzado; el misionero, al adoptar características patriarcales en un espacio merodeado por la rapacidad española, desemboca en la figura del caballero andante, figura que se propone como modelo del accionar heroico de cara a una institucionalidad que no lleva a cabo las tareas que le son inherentes para el buen funcionamiento social. Ante la falla sistémica, la justicia heroica se privatiza y medievaliza, dando surgimiento al Quijote americano.

$\mathrm{Y}$ este dicen ser el principio y fundamento de la orden de caballería, que en los tiempos antiguos, cuando no había tanto poder ni justicia en los reinos para refrenar a los malos hombres y tiranos que hacían agravios y fuerzas a los que poco podían, eran ordenados o armados caballeros los hombres esforzados que se preciaban de más nobles y generosos ánimos, con juramento que hacían de quitar y deshacer agravios, y defender con todo su poder a las personas miserables y destituidas de favor (HEI 2: 106-7).

Que se recurra a tan grotesca mitificación histórica para proponer un modelo institucional alternativo, ilustra la restricción de opciones históricas ante las cuales la única alternativa es el emplazamiento de la propia materialidad en la zona de contacto entre el indio y la maquinaria mercantilista, para, a modo de colchón, aminorar el impacto de ésta sobre aquél. A diferencia de Cervantes, la ironía de la propuesta quijotesca no existe en Mendieta. La posibilidad de una mirada irónica implicaría traspasar los límites ideológicos y prácticos en los cuales Mendieta se ubica a sabiendas, como acto de libertad. En otros términos, su postura es ética, no negociable; se propone como acto de voluntad - porque "así se quiere". El sacrificio cristiano es, en sí, una victoria, en tanto contiene la dignidad del acto y la palabra.

El quijote americano evidencia la crisis del modelo épico del mito cruzado, el desmembramiento del tejido socio-institucional otrora sostenido por la fe en la razón política imperial. La Colonia es vista como un edificio en pleno colapso. La tarea de mantener 
entera esa estructura es una labor mal recompensada, ingrata, quimérica, que lentamente va minando la salud física y espiritual de los "buenos cristianos" - tal el caso del virrey Luis de Velasco, a quien "si alguna cosa particular le acortó los días de la vida fué la gran pena y lástima que tenía de ver su perdimiento [de las colonias], y entender que no era parte para tener en pie lo que se iba cayendo" (CM 1:31). La pérdida de fe en la política indiana se manifiesta en la conciencia de la incapacidad de las leyes para efectuar cambios significativos en la práctica social; la tarea legislativa se transforma en una empresa quimérica y grotesca, al punto que "darles ordenanzas a nuestros españoles de Indias, es como poner puertas al campo" (HEI 2: 105). El desencanto con la dimensión utópica de la experiencia colonial se expresa también en la reticencia de Mendieta, tras su estadía europea, en retomar la labor apostólica en América (CM 1: 168). La reintegración a la empresa colonial es vista como un "género de martirio" donde el vampiro español ha de consumir las flacas fuerzas del misionero.

[...] puse este poco pecho que tengo á este género de martirio que el Señor me ofrece, aceptando la obediencia y mandato de V. P. Rma., y comenzando con mis flacos y descarnados huesos á ponerme en el camino desta peregrinación, y con mi lengua balbuciente á convidar los siervos de Dios á la cultura de su viña (CM 1: 173).

Junto a la crisis de fe en la razón política, el cuerpo tutelar deja de fungir como ortopedia real y comienza a habitar la institucionalidad colonial como un miembro derelicto, "flaco", desfalleciente, "balbuciente", abandonado por la burocracia real; turbado por transitar un mundo colmado de pleitos y demandas que agotan sus mermadas fuerzas y a nada conducen. Mendieta, cansado y afrentado por el trato recibido en las audiencias, sin ayuda de los hombres, se siente vencido por la magnitud descomunal de las fuerzas que se le oponen; aislado de una metrópolis que es sorda y ciega al drama colonial debido a la capacidad del discurso oficial de crear una verosimilitud acorde a los intereses de la oligarquía española en Indias.

Item, conviene dar aviso á S. M. y á los señores de su Consejo, que pierde muy mucho, mismo que va desfalleciendo del todo la obra en que los Religiosos entendemos de la conversión é instrucción de las ánimas destos naturales, por sernos muchos de los españoles contrarios, pareciéndoles que le somos freno para su demasiada codicia, y así nunca entienden muchos sino en buscarnos tranquillas, $y$ hacer informaciones contra nosotros, las cuales parecen en el Real Consejo de las Indias, y no parecen nuestros descargos ni hay quien responda por nosotros y por nuestra inocencia; ni á nuestro estado conviene tampoco andar en pleitos ni en demandas ni en respuestas ni en hacer informaciones, aunque sea para nuestro abono y justificación; y si alguna vez nos hemos puesto en ello por defender la verdad y justicia, nos hemos inquietado, y al cabo no nos vale nuestro derecho, afrentámonos y cansámonos de andar por las Audiencias, ni tampoco se nos entienden los términos que hemos de llevar en la prosecución de los tales negocios, ni aun hay un escribano que nos quiera dar un testimonio de lo que nos conviene, ni hombre que nos ayude de veras, y así viene á quebrar la soga por lo más delgado, y se da crédito á nuestros émulos porque envían probanzas, las cuales se hacen en esta tierra como las quieren pintar (CM 1: 53). 
El derrumbe del modelo corporativo - un Dios, un monarca, un imperio- deja al religioso en el mutismo dando, por un momento, al traste con el paradigma tutelar. Se transparenta fugazmente la existencia de una subterraneidad discursiva que, aunque el indio esconde por temor, coloca al padre en una situación altamente traumática; el cuerpo ortopédico, momentáneamente confuso, queda sumido en la parálisis del desconcierto, sin saber cómo responder, avergonzado de su propia palabrería cristiana, grotescamente humillado en su incapacidad de producir una práctica que respalde a su discurso con la dignidad de los hechos consumados.

\begin{abstract}
$\mathrm{Y}$ tras estos discursos, concluirán con decir [los indios]: "Si ninguna ley con razón y justicia puede consentir alguna de las cosas aquí dichas, y todas ellas las consiente la ley de los cristianos: luego es la más mala del mundo y digna de ser aborrecida". ¿Quién quita que los indios nos discurran por estas otras semejantes vejaciones que proceden del repartimiento, pues les dio Dios entendimiento como a nosotros, y aun harta más retórica en sus dichos y sentimientos, que la que yo aquí llevo? Sino que con el temor que les tienen puesto, callan y todo se lo tragan. Aunque es verdad que en días pasados a cierto indio, señor natural de una de las buenas provincias de esta Nueva Espana, y tan ladino y entendido como cualquier español, quejándose de la apretura en que un virrey les ponía sobre esto del repartimiento, le oí palabras tan sentidas y tan puestas en razón de hombre, acompañadas con hartos sospiros, que yo (por ser cristiano y español) me hallé el más confuso y atajado del mundo, no sabiendo qué responder, ni como negar la verdad de tan manifiestas y cristianas razones. Y ciertamente digo, y es así, que con harta vergüenza se les predica a estos el Evangelio de Cristo, porque si osasen hablar, muy justamente nos podrían decir a los españoles lo que dice el italiano: "Fate fate, non parlate" (HEI 2: 102).
\end{abstract}

El espacio público, ante el silencio avergonzado de un misionero incapaz de proferir argumentos convincentes, se abre al recriminante discurso del otro, ante el cual no hay respuestas posibles, por cuanto no existe orden alternativo en que fundamentarlas.

Perdido en la sinrazón de ese orden mercantilista de máscaras, sin interlocutor reconocible, la voz del santo, antes extensión de la lengua real, se eleva al cielo para convertirse, de acto político, en clamor desesperado, desesperanzado y monumental. El habla, la interlocución inscrita en la intersubjetividad, en el circuito semiótico que atraviesa la institucionalidad social, se convierte en un acto puramente expresivo de la interioridad, que sólo persigue la catarsis, el desahogo: "Y pues para el bien y reparo destos reinos no somos [los religiosos] parte ni se nos da crédito á nuestro parecer, no es justo que lo demos para los medios de su perdición. Lo que haremos de nuestra parte será llorar en nuestros rincones los males que sentimos, poniéndolos en las manos de Nuestro Señor Dios" ( $C M$ 2: 33-34). El cuerpo se arrincona, se desconecta del funcionamiento institucional y solo llora e implora, es decir, gesticula a Dios sin mediaciones.

La irrupción del fracaso en la $H E I$ lleva a Mendieta a introducir y explicar cambios de tipo genérico en su historia, la que, en lugar de terminar en alabanza, se propone como un plañidero testimonio de la tragedia colonial desde el arrinconamiento y la sordera institucionales. 
Si el progreso de la conversión de estos indios de la Nueva España hubiera tenido el fin y remate de aprovechamiento y aumento como lo suena el título de este cuarto libro, conforme a lo que pedía la razón y la muestra de sus buenos principios, justo fuera que yo lo concluyera con un cántico de alabanzas bendiciendo a Dios. [...] Más como yo, habiendo gozado (por la gracia divina) de buena parte de aquellos prósperos principios, haya visto los adversos fines en que todo esto ha venido a parar [...] no sólo no puedo ofrecerle cántico de alabanza por fin de mi Historia, más antes (si para componer endechas tuviera gracia) me vendría muy a pelo asentarme con Jeremías sobre nuestra indiana Iglesia, y con lágrimas, sospiros y voces que llegaran al cielo (como él hacía con la destruída ciudad de Jerusalem), lamentarla y plañirla, recontando su miserable caída y gran desventura. [...] Sino que tengo por mejor (como de más provecho) usar de este medio en solo el rincón ante el acatamiento divino, y en lo público volverme a ese mismo Dios (en cuya sola y poderosísima mano consiste el remedio), convidando por esta vía a los que le aman y temen, para que leyendo este capítulo me ayuden a se lo pedir (HEI2: 122).

El abandono de la razón político-institucional resulta en la crisis del parapeto documental y su lógica arbitrista, y sólo deja abierta la producción de un parapeto corporal, donde la individualidad ha de lanzarse a los abismos de la degradación colonial para quedar clavada en ella. Perdidas las mediaciones institucionales y políticas del imperio, Mendieta sólo puede recurrir a su propio cuerpo, como única garantía de la acción ética. Con el fracaso de la razón política se supera definitivamente el paradigma cruzado para entrarse de lleno en la disolución empírica en la materialidad americana.

Según el nuevo entendimiento de la corporalidad, la historia colonial aparece como escindida entre la historia verdadera (en la que se expresa el misterio divino a develar) y la historia distorsionada (que oculta una presencia satánica). Una vez más, entonces, el discurso histórico se inserta en el modelo alegórico agustiniano, donde la historia humana es la expresión de la lucha entre el bien y el mal. Sin embargo, se dará en Mendieta una modulación particular que apunta a la disolución del historicismo martirológico de la tradición hagiográfica. La verdadera historia es el resultado de la acción de Dios sobre la tierra, expresándose a través del ser humano. Esta presencia humana sólo es hacedora de historia (divina) en tanto el sujeto histórico es la persona, el sujeto moral -la persona como la encarnación de una ética que moviliza al cuerpo hacia una praxis cristiana. Desde estos parámetros, Mendieta presenta una sociedad huérfana de autoridad "verdadera", donde prolifera la heterogeneidad y la heterodoxia; sin control institucional, donde las relaciones de poder responden al azar coyuntural de una lucha primitiva (regida por el favoritismo y el fin de lucro) dirimida entre aristócratas, militares, burócratas, religiosos seculares y comerciantes; lucha donde los sujetos de moral son desplazados por los sujetos de acción, es decir, por roles actuados por individuos amorfos y amorales, seres enmascarados, que proponen una historia falsa y picaresca.

En la necesidad de captar esta realidad colonial en todo su deterioro y degradación manteniendo, simultáneamente, la visión providencial del imperio como tarea civilizatoria y evangélica, Mendieta produce un dispositivo destinado a mediar ambas concepciones discursivas: esa mediación se articula desde el decoro y la creación de un parapeto documental y hagiográfico. Según este recurso, la aparición de la máscara picaresca que asola la ciudad colonial queda inscrito como un vacío de humanidad que en el discurso histórico 
de la $H E I$ se expresa como anonimia histórica. De allí que desaparezcan los nombres de todas las figuras que conforman la historia menuda de los abusos indianos. Desde el fin de la Edad Dorada, coincidente con el término de la gobernación de Luis Velasco, deja de nombrarse a los curas, religiosos y virreyes coloniales, produciéndose un efecto de anonimización de la historia que pasa a caracterizar la Edad de Hierro colonial.

No se nombra, pero se historia. En otras palabras, Mendieta relata las barbaridades perpetradas desde el poder colonial - y su HEI, puede decirse, es una empresa de fijación en la memoria histórica de ese orden diabólico y sus estragos en América- pero desde la economía simbólica del decoro, que relata pero no nombra. El no decir más allá del decoro marca un hiato entre lo dicho (denuncia de la injusticia) y lo representado históricamente (el autor de esa injusticia). Esta práctica implica un entendimiento de la corporalidad como lugar donde confluyen la divinidad y lo humano. La contrapartida natural de esta visión del cuerpo cristiano es la aparición demoníaca, la materialidad no cristiana (que no es cuerpo), innombrable (que no es persona) pero no impensable. Esa innombrabilidad y descorporizacion grotesca del otro (que aparece como máscara, como ser habitado por una profusión de fuerzas ciegas) señala los límites de una representación ideológica basada en la confluencia de lo utópico, lo material y lo ético como configuradores del orden natural. Existe, desde esta perspectiva, una relación directa entre la oposición persona-anonimia, su universalización teleológica (historia verdadera-historia falsa ) y el entendimiento historiográfico (realismo-distorsión). Por eso Mendieta comienza su HEI con una detallada narración de los personajes heroicos de la conquista y termina con un catálogo de santos y mártires que restituyen el carácter salvacional-histórico de la empresa colonial. Ante la institucionalidad picaresca, anónima y fría, que se denuncia como proliferación de máscaras, se hace presente la historia de unos cuerpos que forman la argamasa que ha hecho posible la historia americana.

Mientras esta labor hagiográfica permite reconstituir la historia americana como expresión de la historia de la salvación universal, la conexión de esa corporalidad con la institucionalidad metropolitana queda restituida por la reproducción de una copiosa documentación que muestra la esmerada preocupación del rey por los indios. El monarca y la producción documental de protección al indígena aparecen como la materialidad en que se sustenta la legitimidad referencial (histórica, concreta) de la utopía cristiana. Las leyes, bulas, memoriales y cartas se muestran como una evidencia de esa presentida e irrefutable presencia utópica: el principio moral encarnado en la persona que llena y sostiene un espacio social poblado por la anonimia de pícaros enmascarados y malos consejeros: “ $\mathrm{O}$ Oh falsos servidores y inicuos aduladores, que engañáis a los reyes so color de servirles, con infernales trazas de augmentarles las rentas, y buscáis solos vuestros intereses y mejorías, destruyéndoles a sus vasallos y reinos! Destruya Dios vuestras trazas y consejos" (HEI 2: 86).

Se trata, en definitiva, de llenar los vacíos coloniales con documentos y biografias santas, en un llamado a vivir la utopía como verdadero hacer histórico, mediante el emplazamiento de la persona en la materialidad degradada de la Colonia. Poblar de leyes y nombres, erigir ese parapeto jurídico-hagiográfico es poder retomar el discurso alegorizante de la historia providencial desde una nueva sensibilidad; es hacer regir el orden alegórico una vez más, después de la disolución empírica en la superexplotación 
americana. La alegorización se plantea, desde esta perspectiva, como un instrumento de articulación ético-práctica en pro de los derechos humanos del indio americano. Expresa, al tiempo que una visión alienada de la realidad colonial, una libertad espeluznante, que el santo ha de garantizar con el emplazamiento de su propio cuerpo en una continuidad discursiva y práctica que conforma uno de los más impresionantes espectáculos del orden colonial.

\section{Trabajos cItados}

Cortés, Hernán. Cartas de relación de la conquista de México. Madrid: Espasa-Calpe, 1970.

Dussel, Enrique. Desintegración de la cristiandad colonial y liberación: perspectiva latinoamericana. Salamanca: Sígueme, 1978.

Hanke, Luis. Bartolomé de las Casas, 1474-1566: bibliografia crítica y cuerpo de materiales para el estudio de su vida, escritos, actuación y polémicas que suscitaron durante cuatro siglos. Santiago de Chile: Fondo J. T. Medina, 1954.

Icazbalceta, García. Códice Mendieta: documentos franciscanos, siglos XVI y XVII. 2 volúmenes. Guadalajara: Biblioteca de Facísimiles Mexicanos, 1971.

Lucena, João de. Historia da vida do padre Francisco de Xavier e do que fizeram na India os mais religiosos da Companhia de Jesus. Lisboa: Pedro Crasbeek, 1600.

Mendieta, Jerónimo de. Historia eclesiástica indiana. 2 volúmenes. Francisco Solano y Perez-Lila, editor. Madrid: Biblioteca de Autores Españoles, 1973.

Pané, Ramón. Relación acerca de las antigüedades de los indios: nueva versión con notas, mapa y apéndices por José Juan Arrom. México: Siglo Veintiuno, 1984.

Pastor, Beatriz. Discursos narrativos de la Conquista: mitificación y emergencia. Hanover: Ediciones del Norte, 1988.

Ruiz de la Peña, Juan Luis. El hombre y su muerte: antropología teológica actual. Burgos: Aldecoa, 1971.

Solano, Francisco y Perez-Lila. Historia eclesiástica indiana, 2 volúmenes. Madrid: Biblioteca de Autores Españoles, 1973.

Vidal, Hernán. Socio-historia de la literatura colonial hispanoamericana: tres lecturas orgánicas. Minneapolis: Ideologies and Literatures, 1985.

Williams, Sam K. Jesus' Death as Saving Event: The Background and the Origin of a Concept. Montana: Scholars Press, 1975.

Zamora, Margarita. Reading Columbus. Berkeley: University of California Press, 1993.

Zubillaga, Lopetegui. Historia de la iglesia en la América española. Volumen 1. Madrid: Biblioteca de Autores Cristianos, 1965. 
